\title{
Enrique Lihn: una estación en Lima
}

Roger SANTIVÁÑEZ / Princeton University

\section{Resumen}

Se desarrolla y analiza el proceso poético de Enrique Lihn durante su estadía en Lima en los años 70. Ello a través de su poemario Estación de los Desamparados (1982), donde se referiría al estado de pobreza social e inequidad permanente en el Perú.

\section{Palabras clave:}

Lihn, poesía latinoamericana, pobreza, inequidad.

\begin{abstract}
This essay develops and analyzes Enrique Lihn's poetic process during his visit to Lima in the 1970's. The study takes into consideration the book of poems entitled Estación de los Desamparados (1982) in which he talks about poverty and social inequality in Peru.
\end{abstract}

\section{Key words:}

Lihn, Latin American poetry, poverty, inequality.

En febrero de 1972 Enrique Lihn fue invitado por el poeta peruano César Calvo a formar parte del Jurado del Festival Internacional de la Canción de Agua Dulce, realizado en la playa limeña del mismo nombre durante el gobierno reformista del general Juan Velasco Alvarado. En efecto - desde el golpe militar del 3 de octubre de 1968- un inédito proceso de reformas estructurales sacudía la sociedad peruana. Llamó la atención del mundo 
entero el hecho de que el golpe no instaurara la acostumbrada dictadura militar-gorila latinoamericana sino que dispusiera una serie de medidas que irían a cambiar la faz del Perú para siempre. A los pocos días de tomado el poder el gobierno de Velasco nacionalizó la extracción y refinamiento del petróleo, hasta entonces en manos de la I.P.C. (International Petroleum Company), subsidiaria de la multinacional norteamericana Standard Oil, situada en la piurana zona de La Brea y Pariñas, símbolo de la penetración imperialista de los Estados Unidos en el Perú y caro anhelo de la reivindicación nacional postergado durante décadas por todos los gobiernos oligárquicos que precedieron a Velasco. Otra medida central fue la Ley de Reforma Agraria - una de las más avanzadas en su época - bajo cuyo lema La tierra es para quien la trabaja fue expropiada casi la totalidad de la propiedad terrateniente y entregada al campesinado organizado en cooperativas o sociedades agrarias de producción e interés social. Hubo otras medidas importantes, como la ley de la Comunidad Industrial, mediante la cual la clase obrera obtuvo el derecho de sentar a un representante en el Directorio de cada empresa y al $10 \%$ de las ganancias anuales de la producción. La ley de la Reforma Educativa y la apertura de relaciones con Cuba y los países de Europa del Este (antes completamente prohibidas) así como la promoción de la cultura nativa (se oficializó la lengua quechua) las artes populares y la nueva canción. En este último sentido debe comprenderse la organización del Festival de Agua Dulce, que contó con la participación de renombrados compositores e intérpretes de la canción protesta como Soledad Bravo, Dante Viglietti, Geraldo Vandré, Alfredo Zirarrosa, Los Compadres, entre otros - como Víctor Jara o Mercedes Sosa, que si no estuvieron allí, visitaron el Perú a la sazón llevando un mensaje de cambio y conciencia en su canción.

Pero lo fundamental de todas estas medidas $-\mathrm{y}$ en relación con algunos poemas del libro Estación de los desamparados de Enrique Lihn que pronto entraremos a analizar - fue el hecho de que - por primera vez- se le dio dignidad al nativo peruano, conocido desde la conquista española como indio o cholo. Efectivamente, la masa campesina (aquella sobre la cual había Ilamado la atención Manuel González Prada en su famoso Discurso del Politeama en 1888) se debatía en la noche oscura de la miseria y la ignorancia, encerrada en una virtual inexistencia político-social frente al Perú oligárquico, en el cual poco más de cincuenta familias provenientes desde el principio de la dominación española detentaban todo el poder. Por esta razón se dijo que el gobierno de Velasco quebró el espinazo de la oligarquía. En realidad la hizo desaparecer como clase y con ello transformó la sociedad peruana por entero. Es decir, dándole dignidad al indio (y demás sectores explotados y humillados por siglos) lo elevó como siempre debió ser - a la categoría de persona humana y lo convirtió en un ciudadano común y respetable. Más allá de los errores a los que pudo 
estar sujeto el gobierno reformista de Velasco Alvarado y las regresiones que han venido después, el saldo histórico es innegable: el Perú dejó ser una estructura semifeudal y avanzó hacia una modernidad chola cuyo devenir hacia el futuro es lo que se vive actualmente.

Una vez planteado este contexto podemos entrar de lleno al estudio de Estación de los desamparados, libro publicado en 1982 pero escrito diez años antes, durante la permanencia de Enrique Lihn en Lima como miembro del jurado -como queda dicho- del Festival Internacional de la Canción de Agua Dulce. Sin embargo - tal como lo comprobamos en El circo en llamasel más remoto orígen del poemario es un texto denominado Dedicatoria a una puesta de sol compuesto en diciembre de 1968. Lihn escribió este poema en el reverso de una imagen de "una de las versiones que hizo Dante Gabriel Rossetti, de Beata Beatrix" (Lihn 379). Se trata del lejano antecedente de Beata Beatrix, poema aparecido tiempo después, 1975, en su libro Por fuerza mayor, poema que según la página que venimos citando: "Contiene dos oscuridades de referencia, del orden la biografía de la destinataria, y de un recado, una declaración o una misiva en la que se combinan el pasatismo, la persuasión y el sentimiento del fracaso" (379). Pues bien, así nos introduce el poeta a Estación de los desamparados debido a que la segunda parte de la obra titulada Cancionero de la Estación de los desamparados: "Es un relato del recuerdo de los restos emocionales que han quedado tras el final de una relación amorosa" (Foxley 160). Siendo así, para Lihn el libro en su conjunto "constituye la comprobación ulterior de una improbabilidad realizada y resuelta negativamente. Su contrapunto es una suerte de crónica o entrevista privada a la ciudad de Lima, que visité, por segunda vez, en febrero de 1972" (Lihn 379).

El nombre de la primera parte del poemario y que igualmente da título al volumen Estación de los desamparados alude a la estación limeña del Ferrocarril Central del Perú, sita en pleno centro de la ciudad -a una cuadra de la Plaza Mayor y a espaldas del Palacio de Gobierno- en cuyo elevado frontis puede leerse ESTACION DESAMPARADOS. Cabe señalar que dicha estación fue tradicionalmente la puerta de entrada a Lima viniendo desde los Andes centrales y que por lo menos desde los años 20 y hasta el final del siglo XX constituyó el lugar de ingreso a la capital peruana de millares de personas - básicamente de origen campesino- procedentes de la sierra, configurando la inmensa ola migratoria andina que ya hacia 1970 había cambiado el paisaje urbano de Lima y la imagen de la ciudad aristocrática heredera de la fundación española. Al mismo tiempo la palabra Desamparados - poéticamente usada por Lihn - quiere incidir sobre la condición de abandono y desamparo en la que se debatía la gran mayoría del campesinado andino inmediatamente después de arribar a Lima. En efecto, el espejismo del progreso se hacía añicos para las masas 
serranas de indios y cholos ante la cruda realidad de un mundo burgués que los despreciaba, arrojándolos a los baldíos de la desesperación y la marginalidad. Sobre este punto permítaseme un testimonio personal: corría abril de 1986 y Enrique Lihn se encontraba en Lima invitado por la SICLA (Semana de integración cultural latinoamericana) organizada por el primer gobierno de Alan García. Una tarde caminábamos por los alrededores de la Plaza Mayor y Lihn se detuvo un instante contemplando el letrero ESTACION DESAMPARADOS, que ostenta el fronstispicio superior del edificio de la estación del tren, y me dijo: "Mira lo que dice allí, ya está el título de un libro", aludiendo no sólo al lugar de tránsito sino a la situación de los pobres en el Perú y precisamente en el sitio por donde miles de ellos Ilegaban a Lima atraídos por el señuelo de mejorar su condición y - simultáneamente- el dolor del poeta, su "pena personal" (Lastra 66). De hecho, ése fue el conjunto de veinticuatro textos titulado Estación de los desamparados, que conforma la primera parte del libro del mismo nombre y que pasaremos a estudiar en profundidad.

Lo primero que salta a la vista es la ausencia de título en cada uno de los veinticuatro fragmentos que componen la secuencia. Es importante destacar que en aquel momento - después de Escrito en Cuba (1969) y en pleno desarrollo de su poética del viaje - Lihn realizaba una "escritura instantánea, que respondiera in situ al estímulo" (Lastra 65). De allí el fragmentarismo de su poesía en ese tiempo y que según el poeta "llega a su clímax" (65) en París, situación irregular (1977) libro inmediatamente posterior a Estación de los desamparados, donde habría cuajado el mencionado fragmentarismo. En efecto, tal como sostiene Óscar Galindo "La estructura del poema como unidad se disuelve a partir de Escrito en Cuba" (230) y luego en París, situación irregular tendremos a "la fragmentación elevada a la categoría de sistema, el fragmento como género en sí mismo" (230). Esta opción fragmentarista ya está presente en "Estación de los desamparados", cuya composición se sitúa cronológicamente entre ambos libros citados. Veamos lo que dice Lihn sobre la fragmentada secuencia de los veinticuatro textos, en las Conversaciones con Lastra. En una parte habla "del poema escrito en Lima" (66) para apenas unas líneas más adelante afirmar: "Es un conjunto de poemas que, creo, se sostienen - estos sí- individualmente, pero que funcionan mejor como un conjunto" (66).

Se trata pues de una estructura bipolar en la que alternan dos posibles lecturas que se complementan: como textos individuales y también como un solo poema orgánico. A su vez, el libro consta de dos tipos de composiciones: en diecisiete de ellas el yo poético (en términos que -en general- podemos llamar tradicionales) toma la palabra. $Y$ en las siete restantes una $o$ varias voces en off se expresan directamente configurando plasmaciones textuales concretas del habla coloquial de ciertos innominados personajes. Enrique Lihn lo dice de esta manera en las Conversaciones: "Escribí esos poemas 
sin titularlos, ordenándolos en una secuencia en que alternan las opresivas vivencias personales, el propio desamparo, con ominosas descripciones y parlamentos, especie de entrevistas en verso que hice in mente a mis amigos y a las personas que por alguna razón me llamaron verbalmente la atención" (66). Aquí radica la importancia del contexto sociopolítico que se vivía en Lima -bajo el impulso de la llamada Revolución Peruana del general Velasco-del cual hablamos al comenzar este acápite. Es decir, los siete fragmentos cuya materia textual está configurada por voces en off, registran - casi sin variación alguna - distintas conversaciones y/o discusiones en torno al álgido período que atravesaba la sociedad peruana en el momento de la estadía lihneana.

La secuencia principia con un poema en el cual somos notificados de la situación: el sujeto se encuentra en el Hotel Columbus de Lima, atormentado por su propia neurosis y por el recuerdo de una fallida relación amorosa, la cual está íntimamente vinculada a dicha neurosis. Dice el sujeto en los primeros versos: "El monstruo emerge al atardecer / del pozo en que lo hundimos cada día / y empieza a mezclar su respiración con la nuestra." (Lihn 11). Es interesante comprobar que la denominación monstruo que le da Lihn a su intranquilidad o desazón personal - a su neurosis en una palabrala encontramos ya en su libro Poemas de este tiempo y de otro (1955). En el poema Oración leemos: "Negrura de mi ser, corona mía, diente mío del monstruo / que me espera / en el fondo del sueño" (43) y es significativo también que se trate de una relación amorosa en conflicto. Y además -en ambos casos - monstruo se hace uno con el hablante. Es una especie de alterego que se va mezclando y fusionando con el yo del sujeto. En esto Lihn es fiel a su formativa herencia simbolista y nos remite al heautontimorumenos (el atormentador de sí mismo) de la tradición baudelariana. Volviendo al poema de Estación de los desamparados el monstruo entonces "Da sus primeros pasos en el traspatio, y sin ruido / como si al celador se le cayera un manojo de llaves" (11). El símil es claro: se trata de una condición psíquica opresiva al punto de semejar una prisión, de la cual el poeta inmediatamente reconoce su raigambre literaria: "Esta sombra que cruza por mi frente / es sólo una vieja pero muy vieja metáfora" (11). De este modo el acto de escribir - la poesía - se convierte en el tormento del recuerdo de la persona amada y simultáneamente en el intento de conjurar dicho tormento: "y tú sonríes en otro país a un extraño: / señal de que he caído en mi obsesión / Cada quien lucha a su manera contra las distintas formas del miedo" (11). Pero ésto no es fácil, uno quisiera huir de la neurosis, dejar de escribir y en esta situación se puede llegar a la aceptación del ataque contra sí mismo:

Ante la propia presencia amenazante y anónima

se tiende a desertar de las palabras

Algo más que desolados

a la autoagresión (11). 
Posteriormente nos enteramos del nombre de la causante de la desazón: "La noche se Ilama y no se Ilama Paulina" (12) y a ella se dirige el hablante diciéndole: "Sólo me valgo de ti como de mis propias palabras / para ordenar otra cosa de lo que estoy escribiendo / y que esas palabras no descifrarán" (12). Es decir, el sujeto usa el recuerdo de su frustración amorosa como un pretexto para escribir pero dicho recuerdo está envuelto en el tormento, del cual el sujeto quisiera evadirse aunque la poesía no servirá finalmente para aclarar nada. En un momento tan temprano como 1966 Lihn declaró a Hernán Loyola sobre este punto: "Estoy señalando el carácter quizás necesariamente iluso de los objetivos de la actividad poética. La fuerza de ésta reside en su desesperación" (Fuenzalida 17). Hay una suerte de empantanamiento en el que se debate el hablante, quien opta por recluirse en la "soledad virtualmente desenfrenada" (Lihn 12) de su cuarto del Hotel Columbus, la cual es descrita como "una celda del viejo manicomio donde no sólo se aúlla / porque encontraré esta manera de hacerlo" (12). Es decir, "se escribe como una forma de aullar" (Foxley 160). De allí que esta investigadora haya escrito al respecto: "No he leído libro más desolado y angustiado que éste" (160).

En el segundo poema (o mejor, fragmento) el malestar continúa. A pesar de su brevedad es clave porque dicho malestar llega a un extremo: la conciencia del olvido y la muerte: "Hotel Columbus, punto neutro de una reunión imperdurable, la / que nos permite contra los días como si fueran años / y que a la larga nadie llegará a recordar" (Lihn 13). Progresivamente la situación interior del poeta, "una crisis personal y afectiva" (Foxley 158) se va mezclando con su percepción del entorno peruano:

Pasado y futuro se han invertido, el mañana

será alguna de las otras escenas agolpadas en mi memoria.

Entre tanto el Perú linda en la decepción: así lo veo

rápido rápido en el espejo retrovisor" (Lihn 13).

Carmen Foxley lo pone de la siguiente manera: "La enajenación se extiende a su relación con el tiempo y con su situación de viajero en el Perú" (160). Se trata - en verdad - de una de las características de la poesía lihneana de viaje, ya advertida por el propio poeta en una entrevista concedida a Silvia Lago en 1966, donde a propósito de su libro Poesía de paso dice: "[son] una serie de escritos de circunstancia. Sólo que esa circunstancia llegó a confundirse eternamente con mi personalidad literaria" (Fuenzalida 23). Esto es perfectamente válido para el caso de Estación de los desamparados y su ambiente limeño. Asimismo, es pertinente señalar que este fragmento es el primero en donde se menciona directamente al Perú. La decepción peruana de Lihn cobra un mayor significado si nos atenemos - más allá 
de la invasión de lo afectivo sobre su percepción- a la decepción real que podría haberle causado su estadía en Lima frente a las expectativas que quizá abrigó sobre la denominada Revolución Peruana del general Velasco. De allí cierta ambigüedad frente al tema trasuntada a lo largo de todo el poemario, y que se condensa en la imagen veloz del espejo retrovisor - posiblemente de un automóvil en movimiento - dándonos la sensación de ver las cosas cuando van desapareciendo o cuando nos desengañan.

El siguiente poema (o fragmento) está totalmente centrado en el tema del Perú. El sujeto pasea por un malecón limeño y le habla a un tú (en este caso funcionando como un alter-ego) que viene a ser el propio sujeto. Frente a la bahía de Lima hay dos islas denominadas San Lorenzo y El Frontón, ésta última famoso presidio durante casi todo el siglo XX. Dice el sujeto: "Ves una isla entre otras, perdida detrás de ellas, / y eso es la Isla del Diablo, un infierno en el que no pensó Dante / ni otro cojudo de su raza" (Lihn 14). Obsérvese el uso de la norma coloquial - grosera y cuasi insultante- en el último verso para designar al genio florentino. Cabe señalar que esta actitud desacralizadora estuvo muy en boga por la época en que se escribió el libro al compás de la ola conversacional cuya cresta se vivía a la sazón. Ahora bien, hay una identificación entre El Frontón y la Isla del Diablo en tanto terribles prisiones y de paso toda la sociedad peruana entendida como un lugar infernal. De allí que se continúe con esta pregunta: "¿Es éste un país civilizado?" (14). A lo que el sujeto responderá: "Yo personalmente creo que no. Este es un país bárbaro / que vive una guerra permanente consigo mismo, / una guerra no declarada" (14). Evidentemente Lihn se está refiriendo aquí a la profunda escisión nacional peruana. Desde el shock que significó la conquista española contra el imperio incaico, la raza aborígen fue condenada a la explotación económica, la discrimación social y el desprecio racial. En esta condición vivió (o mejor: sobrevivió) el indio y el mestizo - el cholo - durante los 300 años del coloniaje y continuó así con el advenimiento de la emancipación y la república. Sólo con el gobierno reformista del general Velasco se reivindicó al indio y al cholo -básicamente a través de la Reforma Agraria- produciéndose un cambio histórico mediante el cual las masas indígenas adquirieron una dimensión real de personas humanas. Esa es la guerra permanente del Perú consigo mismo de la que habla Enrique Lihn en su poema, ya que la inmensa mayoría de la población es india o chola y a pesar de ello, debe permanecer sojuzgada. Por eso Lihn la califica como una "guerra no declarada" (14). Es decir, está solapada, escondida por quienes detentan el poder y los privilegios: la alta burguesía aliada con el imperio económico de los Estados Unidos. De allí que Lihn culmine su poema con estos versos: "Se ha montado aquí una gran maquinaria. / La Maquinaria del Ocultamiento de la Verdad en el Perú" (14). Sobre este punto es pertinente el testimonio del propio poeta en sus Conversaciones con Lastra: "Una de las impresiones más agudas que recibí 
en el Perú e inscribí en el poema fue el mutismo desamparado de los indios que iban y venían de la ciudad" (Lastra 66). El panorama está claro y el comentario social de Lihn se incorpora a su poética.

Prosigue el cuarto fragmento inaugurando un tono que podríamos llamar turístico-crítico y que también se hace presente en los fragmentos décimonoveno y vigésimo. Los estudiaremos aquí como una serie. En el primero de ellos, el hablante se encuentra en una iglesia colonial de Lima, comentando lo que ve, principalmente cuadros religiosos, no sin cierto humor irónico: "Llovieron querubines para todo servicio / Acá desplazan una pesada corona y la suspenden / justo en el punto en que aplastaría a la Virgen" (Lihn 16). Siguiendo esta línea llama a los querubines "lapsus con alas" (16) pero define a "la vieja pintura que se apoyaba en ellos" (16) como "incapaz de elevar una oración real" (16). Es decir, hay un reclamo linneano basado en su no ocultada religiosidad íntima. Puede decirse que Lihn critica aspectos o formas exteriores del comportamiento de la Iglesia pero no la esencia de ella. De allí que haya una especie de nostalgia lihneana en ese reclamo por una auténtica oración. Esto no le impide cierto sarcasmo cuando describe - posiblemente - un cuadro de la Escuela Cuzqueña: "El Arcángel del Arcabuz / Una muchacha / Un hermafrodita con las alas pintadas" (16). De igual modo ve otra imagen en la que "Santo Tomás de Aquino / fulminaba al demonio con su pluma" (16) y comenta: "La Suma Teológica / nunca lo supo: era literatura." (16). Es decir, hay un afán desacralizador en Lihn que busca derrumbar ciertos mitos ideologemas cristianos - y lo hace - simultáneamente - con una crítica implícita del capitalismo: "Virgen arcángeles apóstoles querubines y gente de la familia:/ los donantes multiplicados por sus sillas en una sala de espera. / Sesión de Directorio de la Santísima Trinidad" (16). No es casual este juego de identificaciones entre el Capital y la Iglesia. Inmediatamente denuncia la imposición de la nueva religión durante la conquista española y la avaricia de los conquistadores por el precioso metal:

Todo esto chorrea de bordados de oro

de la presencia del oro, del oro que trajo la muerte al Incanato

y por el cual la vieja España de dientes careados

impuso a Dios a sangre y fuego (16).

El fragmento décimonoveno trata también de una visita turística guiada, esta vez por las catacumbas de un convento colonial del siglo XVI, sobre cuyos habitantes se nos dice que "Fornicaban entre ellos y en otras de sus largas horas de ocio / desgranaban la espina dorsal de sus mayores / transformando las vertebras en estrellas y rosas:" (34). Al final del texto el guía -quien es el hablante del poema- sugiere la entrega de un óbolo 
económico: "Esta es una alcancía / El Convento no recibe subvención del Estado / Más rápido, más rápido o nos quedamos a oscuras." (34). Lihn pone en boca del guía su protesta por la dejadez estatal ante los atractivos turísticos del país y asimismo hace gala de un muy bien manejado coloquialismo transcribiendo - tal cual- la expresión del guía cuando se refiere al cierre del lugar a las visitas del público: "Rápido por favor / Ahoritita no más apagan las luces" (34). Continúa el breve y muy interesante fragmento vigésimo. Aquí Lihn dirige su artillería contra Pablo Neruda, autor del famosísimo poema Alturas de Machu Pichu. Contraviniendo cualquier sentido común al respecto empieza así: "No me provoca ir a Machu Pichu" (35). Es decir, Lihn rechaza la idea de parecerse a Neruda, ni siquiera en el hecho de visitar ruina arqueológica tan importante y mucho menos por supuesto en escribir algo sobre ella. Más bien desea volver a Chile y compara su estado anímico con la conflictiva pasión amorosa por Paulina: "Apuraré mi regreso / pero igual estarás a mil años de distancia / y tú serás mi ruina." (35) hasta el punto depresivo de añorar la muerte: "Fue así como llegué / a envidiar / a los muertos."(35). Más adelante veremos cuán presente está la muerte y el peso de su significado en este poemario. Podemos coincidir con Carmen Foxley cuando afirma que en estos fragmentos: "se registran las experiencias de un turista que arrastra consigo la más honda desolación y desamparo" (158).

A partir de ahora, entraremos a estudiar lo que consideramos núcleo central de esta parte del libro: los fragmentos elaborados con las voces en off. Señalemos con Óscar Galindo -en su artículo Mutaciones disciplinarias en la poesía de Enrique Lihn - que estamos ante "Otra modalidad discursiva [que] es el registro testimonial, la polifonía testimonial" (233). Como ya hemos adelantado párrafos atrás, se trata de una "transcripción testimonial, donde lo distintivo no es el relato de la propia historia de vida, sino la transcripción del relato de otro" (233). En efecto, se trata de textos construidos "a partir de los fragmentos de conversaciones reales sostenidas con amigos peruanos sobre problemas de política contingente" (233). Así podemos leer en el quinto poema:

El pueblo adoptará sus propias decisiones.

Nunca he creído - le contestaron - en la espontaneidad de las masas.

Por el contrario - dijo- sin esa espontaneidad estaríamos perdidos

¿Cómo dice? -le dijeron- ¿Cómo dice? Aló, aló, aló.

Nada . Corte -terció una voz desconocida-. Su teléfono está malo. (Lihn 17)

Es una típica discusión política de la época velasquista entre personas de izquierda. El debate gira en torno a las medidas tomadas por el gobierno 
de Velasco y la actitud que debía tener la izquierda - principalmente marxista - frente a ellas. Ese es el meollo de la confrontación de ideas que presenta el poema. El proceso de la autodenominada Revolución Peruana desconcertó a los grupos marxistas. A eso se refiere Foxley cuando dice que Lihn, "vinculado a intelectuales e ideólogos de ese país, recoge como por azar y reproduce los diálogos de los peruanos, quienes debaten apasionadamente las vicisitudes de una circunstancia política y cultural conflictiva e inmanejable" (158). Ahora bien, Lihn no plantea ninguna solución, sólo expone la situación "desde su lugar de testigo" (159). Y el texto se resuelve en un corte de la conversación entre las partes involucradas. Para Foxley la situación se presenta "decididamente paródica e irónica, pues escenifica concretamente un diálogo de sordos entre varios interlocutores, que más que reunidos en un intercambio de opiniones parecen estar separados por algún ruido de fondo que impide la comunicación." (164). Ese ruido de fondo es la olla de grillos de la sociedad peruana - escindida y fragmentada- carente de un proyecto común que permita un destino colectivo para la nación. Aquí calza muy bien la opinión de Galindo, según la cual: "El mundo representado se define por su carácter fragmentario y difuso, por lo que la escritura adopta los rasgos de esa realidad fragmentaria" (230). El poema (o fragmento) séptimo abunda en el tema de la izquierda. En este caso sobre sus divisiones internas:

Yo viendo las cosas en criollo

voy a decir que la ultradivisión de la izquierda

es sólo una pelea entre perros y gatos

por cosas nimias y cuestiones personales (Lihn 19).

Y por supuesto, siempre en relación al gobierno reformista militar de Velasco: "Estos caballeros pecan de lo mismo que los señores generales / Plantean las cosas en un lenguaje deslumbrante / pero a la hora de los loros lo que cuenta es la champa. (19) acabando en "la incoherencia y previsibilidad de esos discursos" (Foxley 164): "y la lucha armada y la lucha ideológica / deben incluir un gran programa contra el dinero" (Lihn 19). Cabe señalar para ilustrar mejor este tema que la izquierda marxista peruana -teniendo como su más lejano antecedente la fundación del Partido por José Carlos Mariátegui en 1928- a la sazón estaba dividida en muchos grupúsculos de la variopinta gama del maoísmo, trotskismo, guevarismo y la línea pro-soviética; escisiones que se multiplicaron aún más frente a la coyuntura del gobierno del general Velasco, debido a las muy distintas y variadas caracterizaciones que dichos grupúsculos hacían del proceso reformista militar. En este sentido es interesante el noveno fragmento. Allí podemos leer: 
Los años sesenta fueron buenos. Yo diría que hasta el sesenta y tres.

El sesenta y cuatro la cosa empezó a declinar

Entonces ¿eh César? hasta tú,

hasta Antonio Corcuera andaba con una pistola. (21).

El interlocutor del poema es el poeta peruano César Calvo (quien invitó a Lihn para ser jurado del Festival de la Canción de Agua Dulce en Lima) y parece ser tambien quien inicia la conversación poniendo como fecha límite del tiempo dorado de los sesenta el año 1963, evidentemente por el asesinato del poeta Javier Heraud -símbolo de aquella generación- ocurrido el 15 de mayo de dicho año cuando intentaba, junto a una columna del Ejército de Liberación Nacional (ELN), abrir un foco guerrillero. Es pertinente recordar que Javier Heraud y César Calvo compartieron el Premio Poeta Joven del Perú en 1960 y fueron grandes amigos. De allí la mención de 1963 como cierre de una hermosa época de paz y poesía. Si se afirma que en 1964 "la cosa empezó a declinar" (21) es porque en 1965 se iniciaron las acciones guerrilleras del MIR (Movimiento de izquierda revolucionaria) liderado por Luis de la Puente Uceda y prosiguieron las del ELN jefaturado por Héctor Bejar - ambos de raigambre guevarista y cubana. En estas organizaciones participaron - de diverso modo- poetas peruanos de la generación del 60, como Arturo Corcuera, Antonio Cisneros y el propio César Calvo. Dos años después la guerrilla estaba completamente derrotada. Pero en varios puntos de los Andes y en la ciudad de Lima se vivió un clima de violencia, testimoniado en el poema de Enrique Lihn de la siguiente manera: "hasta Antonio Corcuera andaba con pistola" (21) con lo cual -fusionando a los poetas Arturo Corcuera y Antonio Cisneros en una sola persona-quiere significar que -en cierto modo- hasta los poetas (seres pacíficos por definición) de la generación del 60 no pudieron sustraerse de la violencia del Perú de esos años.

El décimo fragmento vuelve sobre las difíciles relaciones de la izquierda con el gobierno velasquista. Es decir, pone en evidencia la sorpresa e incertidumbre de los grupos izquierdistas frente a las medidas del gobierno:

Una esfinge de la ambigüedad

vestida a la usanza militar

que avanzara penosamente arrastrada por el setenta por ciento de la población

sin que se sepa si volteará a derecha o izquierda

por el largo camino siempre igualmente empedrado (22). 
Aquí toma la palabra "Leoncio el Bueno" (22) transformación lihneana del conocido poeta proletario peruano Leoncio Bueno, quien expresaría el punto de vista de la clase obrera politizada. Después de señalar la ambigüedad del gobierno, constatar el apoyo popular, criticar el localismo del proceso: "nos hemos resumido a la cosa puramente peruana" (22), termina por aceptar que Velasco está dando un paso histórico, pese a las trabas puestas por una izquierda incapaz de comprender la importancia de lo que está pasando, dicho ésto con una resonancia vallejiana en el último verso:

Una apertura en las grandes murallas trogloditas

para que entre el aire

Eso sería todo si no dependiera de

nuestra desvencijada izquierda peruana del Perú (22).

Otra voz -ahora totalmente en off, pero que podría ser la del sujeto poético - se expresa en el décimosegundo fragmento: "En Lima, la Tapada, / el general Piérola que ha instalado a su amante francesa en la calle del milagro" (24) y construye una viñeta peruana sobre las banalidades de la historia, pero sintomáticamente el poema finaliza con unos versos que podrían -en sesgo- estar refiriéndose al conductor de la Revolución peruana: "Pero el general-presidente imperturbable sonríe / seguro de marcar el paso de la historia" (24). En el fragmento siguiente Lihn sigue con el tema histórico. Una innominada voz nos deja escuchar:

Porque vean ustedes:

en el Perú, país eminentemente agrario e indígena,

no hay nada que se parezca a la historia.

Digo, a la historia de la lucha de clases. (25).

Es decir, pese a la mucha historia del país, no hay nada que realmente lo sea; o mejor: aunque históricamente las condiciones estuvieren dadas, no ha habido y no hay (no se ve por ningún lado) el enfrentamiento clasista que podría esperarse de dicha situación.

El próximo y breve décimocuarto fragmento es fundamental no sólo en la estructura del libro Estación de los desamparados sino de toda la poesía de Enrique Lihn. Se trata de un arte poética que reza así:

Para ningún destinatario

sin la esperanza ni el propósito de influir sobre el curso de las cosas

el poema es un rito solitario

relacionado en lo esencial con la muerte (26). 
Es decir, en medio de la batahola de los acontecimientos políticos que mayormente vienen ocupando la atención del poeta (una prueba de ello es la transcripción exacta de las voces peruanas discutiendo lo que ocurre) éste llega a la conclusión de que se escribe para nadie. Para nadie y para todos realmente. $O$ sea, no hay un destinatario específico, pero desde el momento en que el poeta ha escrito ya sabe que existe la posibilidad de ser leído, en este sentido escribe para todos (para todo aquel que pueda o quiera leer el poema). Lo que sí está claro es que no hay ninguna esperanza ni deseo de que la poesía influya sobre la historia. La definición de los campos es nítida. No existe en el poeta la menor intención conciente o racional de que su poesía marque en algún sentido el rumbo de la historia. Dicha concepción lihneana es muy importante para comprender que el poeta está solo. Es decir, la poesía tiene su propio campo y sus propias leyes internas. No es tarea ni preocupación de la poesía influir en la historia. Si esto llegara a ocurrir, ya es un asunto ajeno a la poesía en sí, cuyo único fín es la expresión del ser. Como muy bien lo aclara Lihn: la poesía está relacionada en lo esencial con la muerte. El poema dialoga con ella, su único interlocutor válido es la muerte. Es decir, un poema es siempre un comentario de la existencia humana, y siendo así, todo poema lleva implícita la conciencia de la finitud de dicha existencia. En este sentido, el gran tema - aunque el poema no lo toque explícitamente- es nuestra condición de seres finitos cuyo destino invariable y final es morir. En esto Enrique Lihn es muy claro. Su definición de la poesía en estos términos ontológicos, lo coloca en la tradición universal de los grandes poetas. Parecería una contradicción el hecho de afirmar esta condición metafísica de la poesía en medio de una serie de poemas alusivos a una situación política concreta, incluso menuda en lo que respecta a los devenires del Perú en un momento dado de su historia reciente, pero no. Lihn es capaz de ofrecernos un testimonio vivo de lo que está viviendo -viendo y escuchando en su visita peruana - porque no es ajeno a la contingencia de la realidad sociopolítica, pero esto no le impide - sino más bien lo lleva a ella - tener una conciencia clara de la esencia de la poesía. Es decir, en el trasfondo de toda actividad humana - por más doméstica o cotidiana que sea- está nuestra condición insalvable de seres mortales. Y ese es el espacio de la poesía.

El fragmento décimoquinto vuelve sobre la contigencia peruana. Ahora la voz sin nombre nos advierte sobre los peligros del anticomunismo: "La esterilidad del anticomunismo / puede devolver al Perú otra de sus célebres ruinas" (27) pero a pesar de ello se reconoce que algo está cambiando: "Ahora hasta las piedras hablan otro lenguaje" (22). Es decir, hasta los restos arqueológicos deben ser vistos desde otra óptica, así se rechaza la pasatista visión folclórica del tema mediante la ironía: "por favor, nada de tumbas ni de recintos sagrados" (27). El fragmento siguiente es importante 
en la medida en que menciona el título del libro especificando -en la voz del propio Lihn - el porqué de su uso como tal y culminando en una especie de homenaje a las masas populares peruanas expresado en el marco de una honda solidaridad humana:

Estación de los Desamparados: aquí tendrían que llegar

los migrantes de la sierra arrojados a Lima.

Pero con seguridad avanzan penosamente hacia ella

en la dirección de estos cerros hambrientos

donde acampa el ejército de los que mueren y mueren

antes de la batalla,

de los que viven y viven antes de la batalla. (28)

El fragmento que viene está en íntima relación con el anterior y le sirve como introducción. En este poema se va a hablar del indio, es decir de aquellos "migrantes de la sierra arrojados a Lima" (28) pero usando el vocativo problema del indio tal como lo definió José Carlos Mariátegui en su célebre obra Siete ensayos de interpretación de la realidad peruana. Una voz en off a la que pronto identificamos como la de un burgués o pequeño-burgués alienado se expresa en estos términos: "Yo no tengo ninguna solución para el problema del indio: [] La falta de oxígeno a tales alturas podría ser la causa de una disminución del cerebro" (29). La persona que habla está repitiendo un lugar común harto manoseado por la burguesía peruana: el hecho de que por vivir y proceder de los Andes, el indígena peruano tendría una desventaja cerebral debido a la carencia de oxígeno en esa alta zona geográfica. Esta absurda presunción seudocientífica es otra vez rebatida del modo siguiente: "Cuando tú subes a la sierra no piensas con la cabeza: / al atardecer todo es de una tristeza horrorosa." (29). Y luego se pasa a decir que esa sería la razón de la psicología indígena y su desconfianza ante el blanco (o cualquiera que no sea indio) obviando la verdadera razón, es decir, la explotación a la que ha sido sometido desde los tiempos de la colonia. Escuchemos la voz: "Ni modo de comunicarse con ellos, huyen del blanco como del demonio / Qué tal odio carajo. /Es la falta de oxígeno." (29). Luego entra al problema de la desintegración nacional: "No podemos bajarlos a todos de la sierra / ni podemos subir donde ellos están" (30) y la crítica del gobierno velasquista: "Allí la Reforma Agraria distribuye la miseria" (30). Sin embargo el hablante burgués es conciente de que los indios "Son las tres cuartas partes de la población" (30) e irónicamente plantea una solución en contra de sus intereses: "La única solución es que nos arrojen del Perú" (30) para culminar en toda la segunda parte del poema relatando la historia del indio cuando llega a Lima: 
Cuando uno de ellos baja a la ciudad

esto representa una meditación de diez años invertidos en acariciar un sueño de progreso

que se disipa a las veinticuatro horas

En la estación lo esperan para robarle su dinero (30).

El texto finaliza con una cruda ilustración del abuso al que son sometidos los indios durante el servicio militar:

Un tenientillo de bigotes en punta

les ordenaba encuclillarse sobre el lomo de los caballos.

Se azotaba a los brutos para hacerlos emprender una carrera de locos

A quien caía lo castigaban por estúpido:

todos eran pateados en el suelo. (31)

Hábilmente Lihn a través del testimonio del burgués, nos ha expuesto la dramática situación indígena. Y así llegamos a los momentos finales de la estadía lihnena en Lima: "paso una noche última como todas las otras" (36) del fragmento décimoprimero en el que reconoce su tormento interior, es decir, lo que Foxley llama "el desdoblamiento en los roles del personaje autobiográfico" (159) : "A una distancia igual de este mundo y del otro / el pasajero se desnuda sometiéndose a todas las humillaciones de la espera / a un invisible torturador que se disocia de él" (Lihn 36) y termina reivindicando - a sabiendas de su inutilidad - siempre la poesía: "Así todo problema insoluble, por cualquiera que sea, toma / automáticamente el camino de la poesía / que no lo resolverá, para empatar el tiempo" (36). Los tres fragmentos que cierran esta parte del libro son de despedida. En el primero de ellos -el vigésimosegundo- leemos: "Huyo del Perú / hacia el vacío que me espera con sus no brazos abiertos" (37). Lihn se está refiriendo a su regreso a Chile donde lo espera Paulina y su no solucionado conflicto amoroso. Sobre su estadía en Lima comenta: "Buena amistad, / generosa hospitalidad" (37) pero inmediatamente certifica su fracaso personal: "días que pudieron ser de alegría y de valor: / todo, todo perdido" (37) y lo hace con una figura extraída del imaginario peruano: "como un arpista ciego de Ayacucho / el primer día de su llegada a Lima" (37) incidiendo simultáneamente - y otra vez- en el tema de la migración serrana a la capital y señalando una de las zonas más deprimidas de los Andes - Ayacucho- donde, no por casualidad, se inició la insurrección armada que azotó al Perú desde 1980 hasta 1992 convirtiéndolo en el sangriento escenario de una guerra civil que -en cierto modo- intentó hacer volar en pedazos lo que Enrique Lihn llama en uno de los fragmentos 
de este poemario "La Maquinaria del Ocultamiento de la Verdad en el Perú" (14). En el fragmento vigésimotercero nos encontramos con una perfecta definición de lo que es el poemario en su conjunto: "Estas noticias del Perú: notas al margen de un país que como tal no llegará a ser nunca / escrito ni escrito por completo, mezcladas a un problema personal" (38) y en seguida -lúcido como siempre- Lihn reconoce que es un texto cuasi literario, un híbrido diríamos, en su carácter testimonial:

[notas] respetuosas de la literatura

a la que están ligadas por un hilo de araña,

han repetido textualmente

el decir siempre excluyente, en cada caso, de cualquier número de personas

reunidas como cualquier número de personas al azar: (38).

Así plantea un arte poética y siguiendo a Goethe afirma: "El arte - si de ello se tratara aquí- / es la exageración de una verdad parcial" (38). Es decir, hay un vínculo entre lo situado y lo poético, que es a la vez una verdad parcial donde está en juego su problema personal. Y la verdad parcial es la ecuación entre la realidad situada y su visión poética de la misma. El último y vigésimocuarto fragmento ocurre en el avión que lo lleva de regreso a Chile. Algo sucede y en vez de aterrizar el aparato da "una vuelta olímpica" (39) e incluso se encuentra volando hacia Buenos Aires. Entonces una voz en los parlantes dice:

Señores pasajeros

pueden levantarse de sus asientos, establecer entre ustedes un contacto más íntimo.

Nos volveremos a ver en el cielo. (39).

Este interesante verso final, no sólo implica un lúdico despliegue imaginario en Lihn, sino - y así lo interpretamos - una aproximación a la muerte como destino. Y además está testimoniando su deseo de evasión, de no estar - preferiría morir, diremos - al momento de su inevitable llegada a Santiago de Chile, porque allí lo espera el tormento terrible de su problema amoroso con Paulina. De ésto justamente trata la segunda parte del libro Estación de los desamparados, del cual sólo la primera se ha estudiado aquí. 


\section{REFERENCIAS BIBLIOGRÁFICAS}

FOXLEY, Carmen. Enrique Lihn: escritura excéntrica y modernidad. Santiago:

Editorial Universitaria, 1995.

FUENZALIDA, Daniel. Enrique Lihn. Entrevistas. Santiago: J.C.Sáez Editor, 2005.

GALINDO, V., Óscar. "Mutaciones disciplinarias en la poesía de Enrique Lihn." En: Estudios Filológicos 37 (2002), pp. 225-240.

LASTRA, Pedro. Conversaciones con Enrique Lihn. Santiago: Atelier, 1990.

LIHN, Enrique. Estación de los desamparados. México: Premiá, 1982.

---. El circo en llamas.Una crítica de la vida. Ed. Germán Marín. Santiago: LOM, 1997.

*[Fragmento de un acápite del capítulo IV "La voz situada", perteneciente a Enrique Lihn: Una poética del viaje, tesis doctoral de Roger Santiváñez, Temple University, Filadelfia 2008]

Roger Santiváñez Ph. D. (Temple University) es actualmente profesor en Princeton University. Es considerado uno de los poetas peruanos contemporáneos más importantes. Su obra poética es numerosa, siendo lo más resaltante los siguientes libros de poesía: Antes de la muerte (Lima, 1979), Homenaje para iniciados (Lima, 1984), El chico que se declaraba con la mirada (Lima, 1988), Symbol (Princeton, 1991), Cor Cordium (Amherst, 1995), Santa María (Lima, 2001), Eucaristía (Buenos Aires, 2004) y Amásteis (Santiago de Chile, 2007). Fundador del movimiento Kloaka, está incluido en La última cena, poesía peruana actual (Asalto al Cielo/Editores, Lima, 1987), Poesía Peruana Siglo XX de Ricardo González Vigil (Ediciones Copé, Lima, 1999) y La mitad del cuerpo, antología de la poesía peruana de Víctor Manuel Mendiola (Fondo de Cultura Económica, México, 2005). Acaba de publicar Labranda (2008).

royika@hotmail.com

Recepción: 10 de octubre 2009. Aprobación: 25 de noviembre 2009. 